\title{
STRATEGIC IT PLANNING, EVALUATION AND BENEFITS MANAGEMENT: THE BASIS FOR EFFECTIVE IT GOVERNANCE
}

\author{
Peter Marshall ${ }^{\mathrm{a}}$ and Judy McKay \\ ${ }^{a}$ University of Queensland/Mt Eliza Business School \\ 380 St Kilda Road, Melbourne, Victoria, 3000 \\ pmarshal@mteliza.com.au \\ ${ }^{\mathrm{b}}$ School of Information Management \& Systems, Monash University \\ Sir John Monash Drive, Caulfield East, Victoria, Australia 3145 \\ iudv.mckav@sims.monash.edu.au
}

\begin{abstract}
This paper reports on the results of an empirical study into the integration of strategic information systems planning and business-IT alignment, IT evaluation, and the proactive management of business benefits in large organisations, and to consider the linkages evident between these processes. An argument is developed which suggests that at the heart of good IT governance practice is an integrated cycle of building a business case, alignment and prioritisation of IT investments with business objectives and imperatives, evaluation, system acquisition, and post implementation proactive benefits realisation.
\end{abstract}

Keywords IT governance, strategic information systems planing, IT evaluation, IT benefits management

\section{INTRODUCTION}

In contemporary business, there is intense interest in deriving business value form information systems (IS) and information technology (IT) investments through effective IS/IT governance (Agarwal \& Sambamurthy 2002, Shane et al. 1999). In many organisations, investment in IT represents a large proportion of capital outlay, and indeed, IT expenditures often represent the fastest growing category of investment for the organisation (Strassmann 1997). Thus it seems reasonable to conclude that IT assets (in terms of computer hardware, software, telecommunications facilities and human knowledge capital) are very significant, and therefore entitled to thoughtful management and careful attention as to their value and contribution, and return to the organisation (Willcocks 1994). However, concerns are all too frequently voiced by senior management about the size of their firm's investment in IT, and more specifically, about whether the firm enjoys adequate returns on this investment (Willcocks 1996). It could be postulated that developing a sound IT governance framework may move an organisation towards achieving better outcomes with their IT initiatives (Brown 1997)

Currently, management faces some real dilemmas with respect to IT. Firstly, for competitive and political reasons, organisations can rarely exercise a choice not to invest substantially in IT, even when economically they cannot find sufficient justification, and current evaluation practice cannot provide strong grounds for making the investment. Secondly, as IT infrastructure becomes an inextricable part of the organisation's processes and structures, it becomes increasingly difficult to separate out the impact of IT (both positive and negative) from that of other assets and activities. Thirdly, it would appear that comparatively few senior executives feel that they understand IT adequately, despite high levels of expenditure (Willcocks and Lester 1997). The conclusion must be drawn, therefore, that despite misgivings about return on investment, senior management continues to feel pressured into significant investment in IT (McKague 1998).

A number of reasons can be posited as to why there are concerns and perceptions of an inadequate rate of return on investment in IT. Firstly, it could be that there has been an inappropriate investment in and use of information, IS and IT in organisations, and hence concerns about the value of such investments. One often cited example of this stems from a failure to link IS/IT investments with business objectives and strategy initiatives (Edwards et al. 1995, Hochstrasser and Griffiths 1991). Alternatively, it could be symptomatic of a lack of, or ineffective, business and/or IS/IT planning. Over time, a failure to achieve alignment of IS/IT strategies and business strategies could be argued to contribute to disappointing perceptions of IT's contribution to business performance. 
Secondly, it could be that current evaluation processes are either inadequate (or non-existent in some organisations), or that inappropriate evaluation techniques are being used (Willcocks and Lester 1997). Perhaps a lack of confidence in the tools available leads to less than satisfactory practices. Thirdly, it may also be that an inadequate rate of return on IT investments arises because there are inadequate managerial procedures put in place to ensure the realisation of benefits from IS/IT (Ward et al. 1996, Remenyi et al. 1993). Expected benefits are nearly always identified pre-investment for new systems and technology, but rarely are proactive behaviours adopted and changes made to support the post-implementation realisation and evaluation of these anticipated benefits (Thorp 1998). Fourthly, it may be symptomatic of inadequate IT governance structures and processes that leads to disappointing outcomes, and perceptions of a 'gap' between IT and the rest of the organisation (Ward and Peppard 1996, Peppard and Ward 1999).

Arguably, there are at least four key issues which will impact upon perceptions of the value of IT investments:

- that appropriate levels of business and IS/IT planning are undertaken, with the express aim of ensuring that proposals and priorities for IT investment are aligned with, and directly support the achievement of corporate visions, strategies, and objectives;

- that wide-ranging, qualitative and quantitative evaluation procedures and techniques to assess performance on a range of measures are adopted throughout the life cycle of IS/IT, and that the outcomes of this evaluation are actively fed into managerial decision making and action about on-going investment in that IS/IT;

- that organisations implement explicit procedures to ensure that adequate pre-investment consideration of benefits anticipated from IS/IT is undertaken, and more importantly, that post-implementation of that IS/IT, procedures are put in place to deliberately ensure that anticipated benefits are actively realised and managed over time,

- and that organisations implement an appropriate IT governance framework and sound IT governance practices to monitor and oversee the delivery of business value from IT.

This paper describes a study what examined the role and nature of the processes of IS/IT planning, evaluation and benefits management in contemporary organisations. The study also focused on the intersection between such processes. We would argue that this mix of planning, evaluation and benefits management is a vital part of IT governance, as each of these components adopts a somewhat different (albeit important) focus on the other.

\section{CHANGING NOTIONS OF IT AND BUSINESS VALUE}

A review and analysis of the literature on the connection between investment in IT and the delivery of business value from those IT investments reveals some interesting and important evolutions in thinking about these important issues. While early thinking tended to reflect a view that investment in IT would automatically deliver benefits to the organisation (this point is alluded to in the arguments of Ward and Peppard (2002), particularly in the early chapters of their book), more recent arguments seem to suggest a viewpoint that an integrated set of processes of planning, evaluation and benefits realisation are necessary to create the conditions for business benefits to be realised from IT investments. Arguably, this set of processes constitute the basis for a processual framework to support the governance of IT.

In his 1994 paper, Earl outlined a progression of increasingly mature and sophisticated thinking with respect to IT utilisation in organisations. The essence of Earl's argument is captured below in Figure 1. 


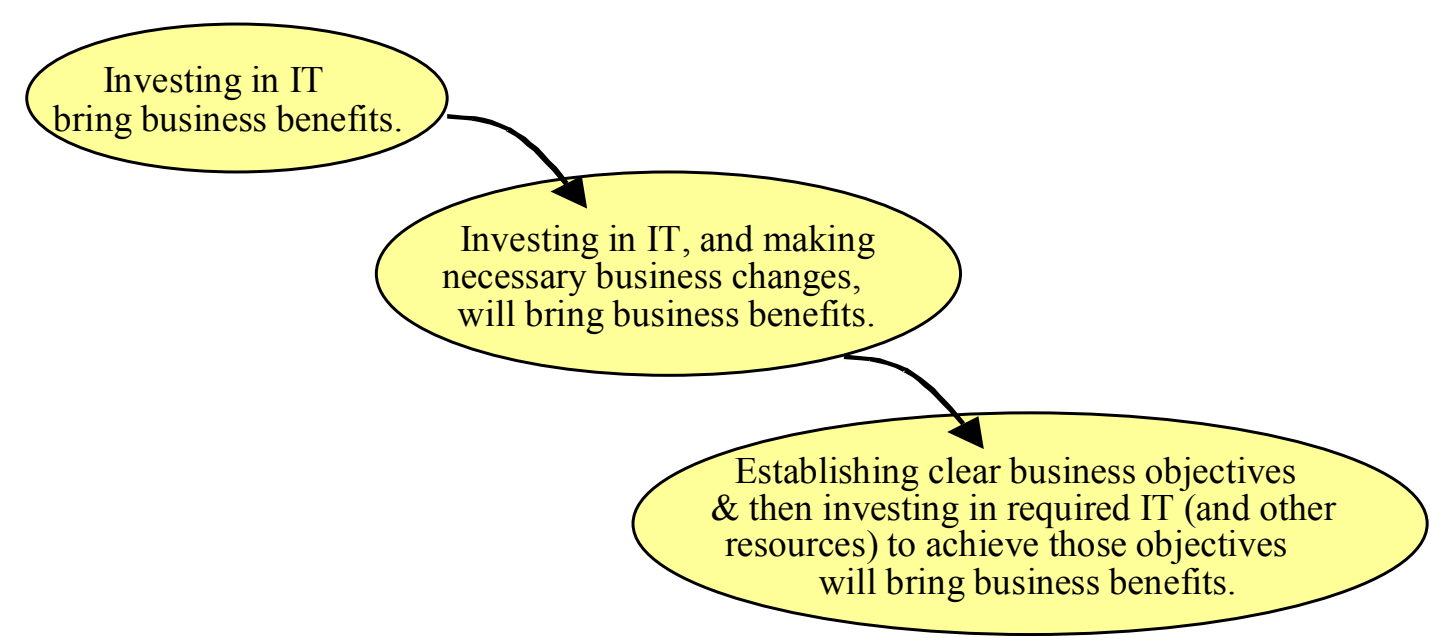

Figure 1: Increasing sophistication with respect to IT

Earl (1994) seemed to be arguing for a move from the "IT is good" mindset, to one that recognised (and practiced) the need for IT investments to be derived from clearly articulated business need(s). Indeed, it could be argued that this type of thinking underpinned much of the work with respect to Information Systems Planning (ISP) that occurred during the early 1990s (Ward and Peppard, 2002). Improving ISP was thus viewed as a serious concern for non-IT and IT managers in industry (Galliers et al. 1994), and much of the focus of ISP was in successfully achieving alignment between business imperatives and IT investments. Methods, tools and techniques were articulated to support this focus (see Ward and Griffiths 1996, Tozer 1996, Earl 1996, for example). While there was a deal of sophistication with respect to the argumentation and approaches articulated, there seemed to be an assumption implicit that desirable outcomes would be achieved if only alignment could be achieved. Thus, in terms of Figure 1, moving beyond stages 1 and 2, and embracing the thinking and actions implied by stage 3 , seemed to be a way of overcoming disappointments with respect to IT investments, as a failure to achieve satisfactory linkages between business and IT initiatives has been cited as a contributing factor to a perceived lack of business benefits from IT (Edwards et al. 1995).

An overlooked factor here may have been the evaluation of IT investments. For the purposes of this discussion, a managerial perspective is adopted in defining IT evaluation as "about establishing by quantitative or qualitative means the worth of IT to the organization" (Willcocks 1992). Concerns have been voiced which suggest that the most frequently used approaches for IT evaluation such as an accounting-based and narrowly focused cost-benefit analysis, may be unsuited to application to some IT projects, and hence may fail to reveal benefits that have been derived from a particular investment (Willcocks and Lester 1997). In addition, some research indicates that formal IT evaluation processes occur all too infrequently in many organisations (Farbey et al. 1993), that formal evaluation is too often limited to project management-type measures of success (Willcocks and Lester 1997), and that inadequate or no evaluation is carried out in a number of cases (Farbey et al. 1993).

One difficulty with all evaluation is that while it may be helpful, indeed essential, to the identification of costs and expected or perceived benefits from a particular perspective, it does little to implement processes and procedures to ensure the management and realisation of those benefits over time. Hence we see the emergence of benefits management approaches which typically institute procedures to ensure the realisation and management of expected benefits throughout the life cycle of an IT investment (Remenyi et al. 1993). Benefits management approaches excel at identifying and managing the achievement of benefits but have few explicit means for linking these procedures to on-going decision making about further investments needed for modifications and enhancements, or actions to terminate, divest or outsource the investment, for example. Thus, 
consideration of Figure 3 leads to a conclusion that there is a need to bring together evaluation and benefits management into an integrated, seamless approach to thinking and acting with respect to IT in organisations. Whereas IT evaluation is concerned with methodologies and processes used to measure the costs and the potential and/or achieved benefits from IS/IT investments, benefits management is concerned with the management and delivery of actual IS/IT benefits to the organisation. However, there is a need to merge or meld these two approaches into a single and effective evaluation and benefits realisation approach, in order to reduce the inconvenience of going through the separate processes for evaluating, and managing and realizing the benefits from IS/IT investments (McKay and Marshall 2000).

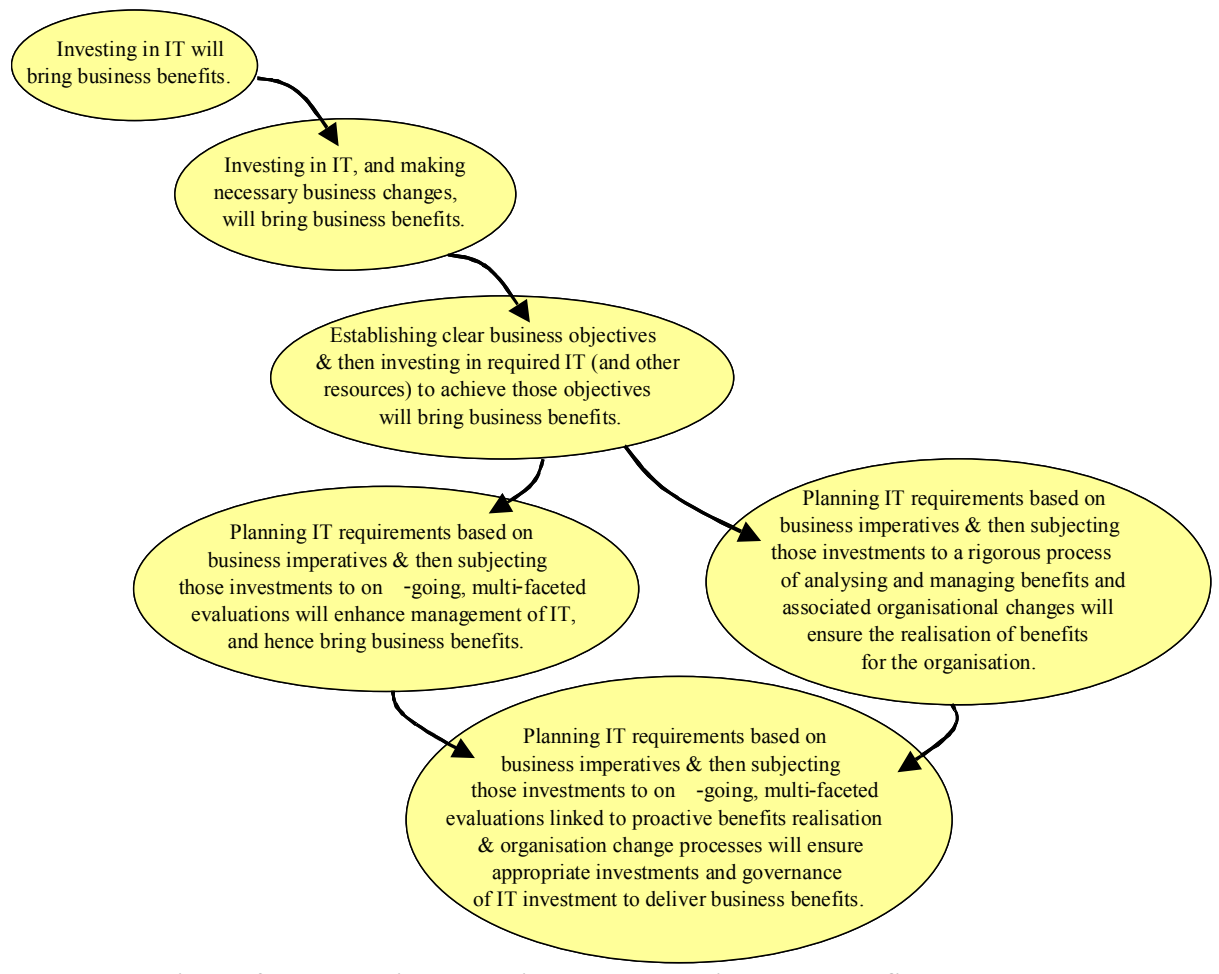

Figure 2: Integrating planning, IT evaluation and benefits management

Thus, the key to effective investment in IS/IT that is acknowledged to deliver value to an organisation over time is an integrated programme of IS/IT planning, evaluation and benefits management that is embedded in the day-to-day routines and rituals of the organisation (McKay and Marshall, 2000). Such an integrated cycle of activities should not only assure sensible and rational commitments to IS/IT initiatives, but also assure that such commitments remain viable, worthwhile and relevant. The authors would argue that for effective investment in IS/IT, a well-integrated and effective set of planning, evaluation and benefits realisation processes is necessary (see Figure 3). Indeed, such a set of processes is central to good IS/IT governance. 


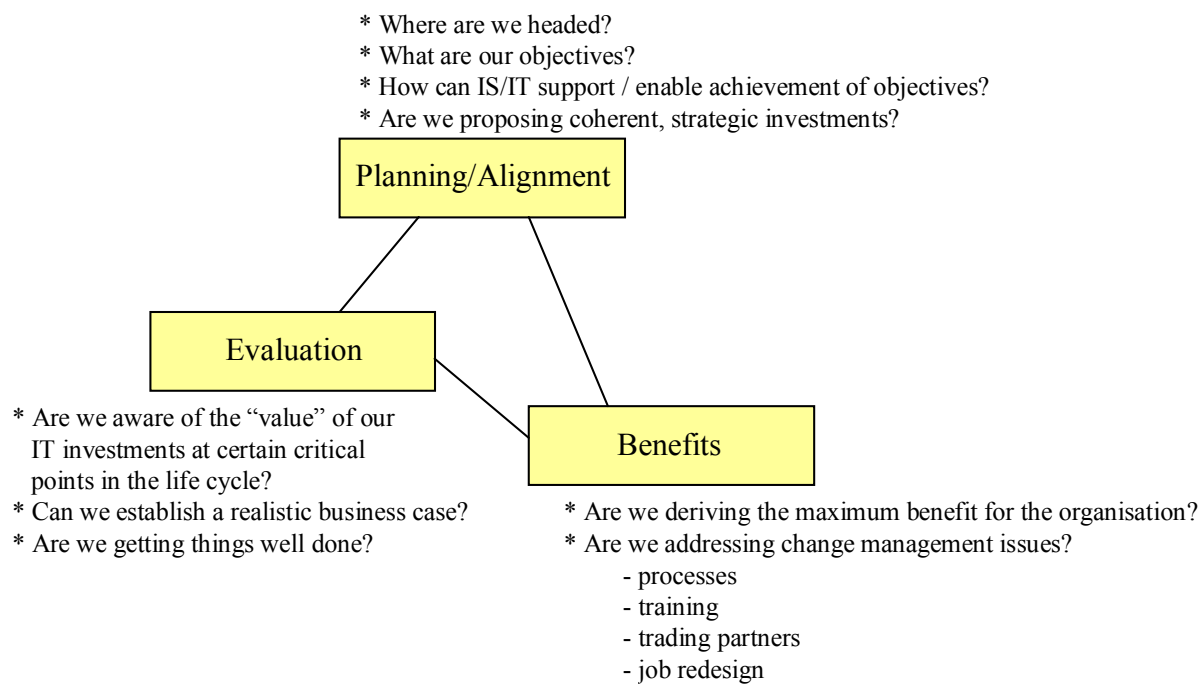

Figure 3: Broadening considerations of the value of IT

\section{RESEARCH METHOD AND DESIGN}

Given the discussions and arguments in the previous sections, the overarching aim of this research was to establish the veracity or validity of the model presented in Figure 3. Thus, it was planned to 'test' the model to see whether empirical data would support such a framework.

The research reported in this paper is part of a larger study into IT governance processes and practices in Australian organisations. Six organisations form the basis for the discussion in this paper. The letters A through to F are used as pseudonyms for the company's involved. They were selected for two main reasons. Firstly, all six organisations, by their own admission, have gone through a 'sea change' with respect to their IT management and governance practices in recent years. Through their own admissions, the CIOs interviewed conceded that their organisation had undergone transformational change with respect to their arrangements for the exploitation of organisation-wide IT capabilities, repositioning themselves from being essentially techno-centric (the IT function is about technical things and does not know too much about the business) to business-centric (the IT function is well integrated with the strategic business units across the organisation and is considered a key business partner on strategic initiatives, of which IT will form an important part). These CIOs also believed that the delivery of business value from IT was now more certain, and had improved dramatically in recent times. None felt that they were "perfect", but these six CIOs expressed certainty that the business contribution of IT had improved, and they now felt they had the support and confidence of other senior executives ${ }^{1}$. Secondly, they were selected on the basis of availability and accessibility.

The research was pursued via qualitative case studies (Benbasat, et al. 1987, Cavaye 1996). The Chief Information Officer (CIO) was interviewed in each of these six organisations, all large, established, successful companies within Australia's Top 500 companies (Baker et al. 2002) ${ }^{2}$. Although this may seem a relatively small sample from which to generalise findings, this number does fit within the guidelines established by Eisenhardt (1989), who recommends a sample of between 4 and 10 for in-depth qualitative case studies. A diverse range of industries from which the organisations were drawn was included to enhance the generalisability of the findings (Eisenhardt 1989). Data collection was primarily through semi-structured interviews (Darke et al. 1998), each

\footnotetext{
${ }^{1}$ Subsequent informal conversations with selected executive level managers in these organisations supported these assertions by the CIO.

${ }_{2}$ In fact, the six organisations included in this paper were all within the top 35 companies in Australia.
} 
lasting between 60 and 120 minutes, and through analysis of internal corporate documents (Strategic Plans, IT Strategic Plans, Policy Statements and so on). In some cases, particularly when executives were based outside of Melbourne, telephone interviews were used in place of face-to-face interviews. All interviews were recorded, and the researchers took notes during the interviews. These recordings were then transcribed, and analysed for emergent issues, patterns of interest, and so on (Darke et al. 1998), with particular attention paid to the CIOs thoughts and statements about IT management and IT governance processes and issues. Our framework for ensuring the delivery of business value form IT (see Figure 3) was used as the basis for our interpretations of the governance activities in each organisation. Interviews were conducted between August and October, 2002.

There is a risk when using a relatively small number of cases that results reflect idiosyncrasies of the organisations involved. However, attempts were made to identify common patterns and trends across the cases and to use that as the basis of any generalisations (Orlikowski 1993). The data was analysed in the first instance independently by both researchers on a case-by-case basis. Categorisations were made of the transcribed data on the basis of the framework for effective IT governance and the key IT governance processes. The two views were then merged, with care taken to adequately deal with differences in opinion and perspective. In the final stage, we undertook a cross-case comparison, thus identifying common trends, patterns and issues of interest in terms of the IT governance processes and behaviours of the six organisations under study. Broad demographics of the companies involved are detailed in Table 1 below. Where no information was offered or made available, a blank has been left in the table.

\begin{tabular}{|c|c|c|c|c|c|c|}
\hline Company & $\mathbf{A}$ & B & C & D & $\mathbf{E}$ & $\mathbf{F}$ \\
\hline Industry & Retail & Pharmaceutical & Manufacturing & $\begin{array}{l}\text { Financial } \\
\text { Services }\end{array}$ & $\begin{array}{c}\text { Leisure/ } \\
\text { Entertainment }\end{array}$ & $\begin{array}{c}\text { Food \& } \\
\text { Beverages }\end{array}$ \\
\hline $\begin{array}{c}\text { Operating } \\
\text { Budget }\end{array}$ & $\$ 100 \mathrm{~m}$ & $\$ 4 m$ & $\$ 35 \mathrm{~m}$ & $\$ 55 \mathrm{~m}$ & $\$ 50 \mathrm{~m}$ & $\$ 52$ \\
\hline $\begin{array}{l}\text { IT as } \% \text { of } \\
\text { capital } \\
\text { expenditure }\end{array}$ & $12 \%$ & $5 \%$ & $7 \%$ & $60 \%$ & $30 \%$ & - \\
\hline $\begin{array}{c}\text { Capital } \\
\text { expenditure }\end{array}$ & $\begin{array}{l}\$ 80- \\
100 \mathrm{~m}\end{array}$ & $\$ 4 m$ & $\$ 7 \mathrm{~m}$ & $\$ 48 \mathrm{~m}$ & $\$ 15$ & $\$ 10 \mathrm{~m}$ \\
\hline $\begin{array}{l}\text { Years as } \\
\text { CIO }\end{array}$ & 3 & 12 & 6 & 4 & 5 & 3 \\
\hline
\end{tabular}

TABLE 1: COMPANY DEMOGRAPHICS

\section{FINDINGS AND DISCUSSION}

Analysis of the interview transcripts reveals broad support for most aspects of the proposed model in Figure 3. While the specific activities, processes and structures to oversee and manage the acquisition of IT varied from organisation to organisation, in all six organisations included in this research, there emerged a pattern of planning, evaluation and benefits management, which broadly can be categorized into five main categories or integrated phases. Each of these is briefly discussed below. Included in the discussion are characteristics of each phase that are regarded as important features of making the phase concerned an effective process or activity.

\section{Phase 1: Building the Business Case}

In all the organisations included, CIOs were very clear on the need for any proposed IT investment to be demonstrably supporting of business goals objectives, and specific business initiatives. They were all very clear on the need for a compelling business case to be articulated before any IT investment would even be contemplated.

D: Our investments today are targeted to support our strategic imperatives - if their strategic imperatives are right then they're the things that count ... we've got to check the allocation to 
[IT] investment is consistent with our strategy which is consistent with our strategic imperatives which is consistent where we want to play in the marketplace in terms of getting a larger share of the business that's profitable

F: Well that depends on the strategy. We go to the business, and say 'What is it that you're trying to do with your business from a strategic point of view that you need our assistance with or that you say you need an IT investment in relation to?' and then each of those will then have to be presented with a business case

In all organisations, the ideas for IT investments in most circumstances originated either from the strategic business units (SBUs), or from joint interaction between IT and the SBUs, but did not arise from the IT department on its own. The only exception we discovered to this was in the case of IT infrastructure investment proposals, where this was more likely to have originated from within the IT department, a finding supported by Weill and Woodham (2002). In initiaves emanating from SBUs, the IT department is involved in the very early stages in the development of initial ideas. Thus, the initiation of IT investments is now regarded as a business responsibility, and the development of the early business case is seen also as a responsibility of the SBU, although the IT department does provide support and assistance in this process, particularly in terms of what is feasible, practicable, and 'do-able" in terms of the organisation's current IT infrastructure and IT skill set.

D: We have business project managers or sponsors who put the business cases up...they're the ones who have said 'If I get to that cost, that functionality, I'll get that revenue or that cost cut'

E: There's an informal process that happens ... and that's really just discussion between product managers deciding that they want innovation - there would be informal discussions with people in IT as to what the technology for that will be - and then it builds into a planning paper - so it might be an initial feasibility paper - which then is teased out into typically more detailed business requirements paper - then around about that stage of the process a capital request would be developed...It's discussed with the steering committee but it's really done at a different level - the plan is developed within the planning process within the divisions

The output of this first phase is an initial business case for a specific IT investment proposal, which has been through some preliminary identification of anticipated costs and business benefits. Sponsorship for the proposal from within the business unit must have been identified.

\section{Phase 2: Alignment and Prioritisation}

Once an SBU believes it has built a compelling business case and a sponsor for the project has been identified, typically organisations in our sample then require the proposal to be scrutinized by another entity or committee, usually associated with strategic planning. This might be some sort of steering committee, it might be conducted within the corporate strategy department, or it might be an independent business project office, but all reported some sort of higher level scrutiny of the SBU proposals. Very large proposals could go all the way to the Board for scrutiny. All the CIOs interviewed reported formal IS/IT planning processes and mechanisms in their organisations, with the typical planning cycle being 1 year (with a 3-5 year time frame). However, these plans and strategies were subject to more frequent reviews, often 3 or 6 monthly, where business goals, objectives, and priorities were re-evaluated, and then IS/IT initiatives re-evaluated in the light of possibly changing business initiatives. It was during this process of strategic planning and review that new proposals for IS/IT investments were considered, with very careful scrutiny of each proposal being conducted to ensure that any resultant IT investment would be aligned and consistent with strategic business imperatives, and that responsibilities for costs and the delivery of business benefits was clearly identified. One CIO interviewed described this scrutiny as "applying a blowtorch to investment proposals". Sensitivity to IT projects failing to deliver on business benefits 
and blowing out in terms of costs was evident, and attempts had been made in all organisations in our sample to effect governance mechanisms to try to prevent costly (and damaging public) failures with IT projects.

A: What we've got is, in each area of our business, we've got business steering groups that, within the budget of that business group, will approve the projects - now they typically approve up to a project of about \$1 million. We've then got an overall IT steering group which is chaired by our Chief Executive and that would approve the larger projects. When they are over a certain size they would end up going to the Board as well

Projects that survived this process were those that could clearly be shown to be aligned with business goals and objectives. Successful initiatives were then prioritised on the basis of the extent to which they were seen to be directly related to key business initiatives, and according to their perceived ability to deliver value to the business. For large initiatives (say those project proposals in excess of $\$ 500,000)$, the organisations in our sample were on average willing to spend between $\$ 20,000$ and $\$ 30,000$ to get to the point of proceeding with or killing off the initiative.

$C$ : We are trying to push away from these projects being seen as IT projects... What we now say is, what's the business's new strategy - this is what we are trying to achieve - oh and by the way we might need some IT to help us with that - rather than IT coming in saying 'If you get SAP you're going to be able to make all these business changes...' So there is a very different approach to it... what happens is that even when something like that gets to board level - it's not being pushed forward as an IT project- so it becomes part of the business project - not an IT project and that's where the difference is I think ...that's not to say that IT isn't going to be out in the industry looking at potential solutions and opportunities and all of those sorts of things - but they need to always be done with a business opportunity in mind not a technology opportunity

F: What is it that you're trying to do with your business from a strategic point of view that you need our assistance with or that you say you need an IT investment in relation to' and then each of those will then have to be presented with a business case

\section{Phase 3: Evaluation}

At this stage, successful projects were typically exposed to more rigorous cost benefit analysis and the like. Thus, although the projects surviving to phase 3 were seen as aligned with business strategy, yet more rigorous assessment of the costs and the likely benefits was considered necessary. Typical of the sentiments expressed are the words of one manager who said, "We don't like surprises". The CIOs were very aware of the apparent ease with which IT projects could get out of control, and hence were careful in conducting rigorous investigation and analysis to prevent this from occurring wherever possible. Again, it was not uncommon for very large projects (say, more than $\$ 1,000,000)$ for perhaps $\$ 200,000-\$ 300,000$ to be spent in refining and firming up in terms of the project scope, its costs and its likely benefits.

E: IT investments...not all of them actually occur because that's the stuff that goes in the planning the board signs off on - but then on a case by case basis you go through this sort of more detailed analysis process, and at that stage the business and the IT guys have go to you've got to commit in - you've got to say - 'I will do this within this cost by this date and achieve this benefit' - so if it doesn't stand up to that more rigorous test - then it doesn't go ahead

At this phase, risk profiles were typically developed for all projects, as risk management was seen as one key aspect of successful project implementations. It was not generally the case that high risk projects were given lower priorities or abandoned, but rather that higher risk projects needed to deliver greater benefits to the business and hence additional efforts to ensure the realisation of those benefits was essential. 
A: it's basically what's the return we are predicting versus the predicted cost with an allowance in there for the risk factor. We would expect a higher rate of return for a high risk project that we're not as competent of delivering

All the CIOS interviewed expressed concerns with their ability to deal with intangible business benefits. Generally speaking, they did not try to allocate dollar values to intangibles, but this did mean that there was still considerable uncertainty as to the value of particular initiatives. Concerns were also expressed about the time of realizing benefits: costs were generally easier to identify and were largely experienced early in the life of the system, whereas benefits often took some time to be realised. Another factor in the delivery of benefits had to do with business change: some CIOs felt that the during the 6-12 months typically required to deliver a project, business change had occurred, reducing the possibility of benefit realisation as business assumptions had changed. The CIOs also commented that it was often difficult to attribute benefits solely to IT: thus benefits were often derived from business change initiatives, of which IT was just one component, and therefore being specific about the benefits realised from just the IT components of that change were extremely difficult to articulate with any precision. The usual problems of enthusiastic project sponsors overstating benefits and understating costs were evident in most of the organisations interviewed.

C: because you do get people that are champions about things or picture certain things, and they are obviously very enthusiastic about what their baby can deliver if you like. And I think that human nature will tend to overestimate the benefits...I can really only think of one major project - there's lots of little things - but one major project where the outcome was a heck of a lot better than expected - anything else is either at or more typically below the expectations

$\mathrm{C}$ : it is a very volatile kind of environment that you work in - and therefore to try and second guess where things are going to be in a year's time is absolutely almost impossible and that's why I think they come in at below expectations - and you can't stop the world while you're delivering a project

Projects at this stage were still subject to being terminated. Many of the CIOs stated that if there were still considerable doubts about the ability of the organisation to implement a viable system that delivered business value, then they would have no hesitation in cancelling the project at this stage.

\section{Phase 4: System Acquisition}

Phase 4 saw the acquisition of the system, with CIOs facing the dilemmas of the build vs buy dichotomy. Thus systems could be sourced through an in-house development project, but more often, it involved procuring packages and customizing them to suit in-house business processes. Customisation was sometimes done in-house, but at other times was left to the software vendor, or recognised consultant, to do. All six CIOs reported they were under pressure not to build systems in-house from scratch.

In five of the six organisations interviewed for this research, the 'buy' model was the preferred, but not sole, approach. The reasons stated for this was generally packaged software was seen as a cheaper option, it was seen as more predictable, and it generally took less time to implement a working system. In the sixth organisation where the norm was to develop systems in-house, and in the other five organisations in those cases where they decided to build in-house rather than buy software, there were a number of compelling reasons why this was done. Firstly, CIOs reported that peculiarities of their business sometimes meant that purchasing systems was not appropriate. Many could identify business circumstances and processes that meant that available software packages were a very poor fit. For example, one CIO had implemented an ERP package, but found that the production and manufacturing module simply did not suit their industry-specific production processes, meaning that their production control system and the like were developed in-house, or alternate modules were sourced from another software company with interfaces and integration 
issues dealt with in-house. Others, particularly those associated with the Finance and Insurance sectors argued that American packages offered an inadequate fit between the Australian business environment, specifically Australian tax laws and regulatory requirements, and the functionality embedded in the software. The third reason stated for in-house development being preferred occurred when there was heavy IT involvement in the product/service mix of the company. For example, in the insurance and financial sectors, CIOs reported that IT support and enablement could no longer be separated out from the product and service being offered. In such cases, in-house development was often the preferred approach.

E: We have a portfolio of contract arrangements. We don't have any full outsourcing, but we have people that provide various hardware services and hardware. We have organisations that from time to time we use to undertake developments, and we buy software products...generic ones, and also applications that might be quite specialised to an industry. We do a lot of development in-house and in part the reason for that is we operate in a specialised area of application where there really isn't a mature market of packaged software...there's not XXXs all around the world running the services we do and even though there is a fairly large population of them, there's an enormous variety in product and also regulatory obligations...so it's hard to get a generic package

Irrespective of the build or procure decision, on-going evaluation and scrutiny of the acquisition process was the norm during phase 4. All organisations reported rigorous governance mechanisms for their major IT projects. The specifics varied, but essentially involved either regular reviews by a steering committee, or involvement of a business project office that oversaw the progress of each IT project. While the evaluation conducted in phase 3 had typically sorted out suspect projects, it was not impossible for a project to be terminated at phase 4 if the entities charged with overseeing the projects felt that costs were escalating, or business benefits becoming less likely to be realised, or the business need was changing, and so on.

D: We have a gating [evaluation] process where people get their money to get through the gates to do the project, so we have gate 0 to gate 1 which is really straight analysis... and there will be an IT business solutions manager involved in that...gate 1 to gate 2 is really high level analysis - not so much high level but it's the step 1 analysis and so on...gate 2 to gate 3 is detailed analysis and so on which just takes that a bit further. There's gates to get through all along the way.

F: We set milestones for each project then re-assess the investment on an ongoing basis...We're very very heavy on strict project management

Many of the CIOs attributed these aspects of governance of reducing runaway projects. The CIOs acknowledged that not all projects were implemented on time and within budget, but did feel that careful management of the project from a business perspective has delivered much better results for their organisations. Most cited now that between approximately $60 \%$ and $80 \%$ of project were on time, and between about $70 \%$ and $80 \%$ were within budget, both figures having shown substantial improvements in recent years.

E: In general, we've been pretty good in terms of delivering things on budget compared with I think a lot of organisations, and I would say probably in the last 6 years we haven't had disasters you know...we haven't had the disastrous ERP project like organisations where you're running $30-50 \%$ over budget or $100 \%$, or you failed to deliver at all. We haven't had any of that, and I think it's actually...in part it's a reflection of how aggressively disciplined the whole investment process is 


\section{Phase 5: Implementation}

Some CIOs described a rigorous process of post-implementation reviews, driven by the business sponsors of the project, with some inputs from IT. Part of this was a review of typical measure of project management success (on time, within budget, to specification). By contrast, some managers felt that extensive post-implementation reviews consumed resources which were needed elsewhere, and another admitted that while important, post-implementation reviews were not routinely done. However, many of the CIOs interviewed typically recognised the perhaps more important requirement to assess the delivery of business benefits (i.e. were the systems, once implemented, actually realizing the benefits identified pre-investment for the business?). Some of our sample organisations had proactive benefits management processes in place, while others conceded that this was important and an area where they needed to improve.

D: We do a post-implementation review and later on you do a benefits audit - that's how I expect it

However, some of the managers were concerned about the resources required to undertake such a benefits realisation process. Take this quote, for example:

A: We certainly do a post implementation review of all our projects but if the question is more around benefits, do we go back rigorously a year later or whatever and say 'okay compared to what we predicted how did we do?' I've got to say we haven't been strong on that as I think we should've been but the other factor of course is that there's always a lot changing in the business anyway, so it's very hard to attribute an improvement to one specific project...it tends to be look we think we've got $80 \%$ of the benefits from what we've already done - rather than put a whole heap of extra effort into chasing proportionately less benefits, let's stop, and accept that there is some weaknesses in what we've done but there are bigger opportunities elsewhere

The issue being grappled with here is that as CIOs, they felt torn between the potential to derive greater benefits from the existing investments, as opposed to diverting resources to exploiting other IT opportunities. Interestingly, our CIOs tended to adopt the satisficing position (i.e. that delivering, say $80 \%$ of expected benefits was probably good enough and that the resources consumed in trying to achieve $100 \%$ or more would be better diverted elsewhere).

\section{CONCLUSION}

The main premise on which this paper has been centred is that organisations may expect better results from their IT investments and capabilities if there are good IT governance processes and mechanisms in place. Part of the governance processes is the development of procedures and structures which support an integrated cycle of strategic IS/IT planning and alignment, evaluation and benefits management. Organisations in this study were well aware of the need for this cycle, but acknowledged that their attention to the realisation of benefits could be improved. The rigour of governance associated with planning and alignment, and evaluation was attributed with reducing disappointing outcomes with IT acquisitions. While accepting that more could be done in terms of the delivery of benefits, the volatile business environment, changing business requirements, and complex, multiple organisational change initiatives of which IT formed one part were all implicated in making it difficult to realise all anticipated business benefits from specific IT investments. 


\section{REFERENCES}

Agarwal, R. and Sambamurthy, V. (2002) Principles and models for organizing the IT function. MIS Quarterly Executive, 1(1): 1-16.

Baker, J., Baker, L., Nadi, S., Ng, P. and Kaseman, P. (2002) The Top 500. Business Review Weekly, April 24-May 1, 2002:64-65.

Cavaye, A.L.M. (1996) Case study research: a multi-faceted research approach for IS. Information Systems Journal, 6(1996): 22-242.

Darke, P., Shanks, G. and Broadbent, M. (1998) Successfully completing case study research: combining rigour, relevance, and pragmatism. Information Systems Journal, 8(1998): 273289

Eisenhardt, K.M. (1989) Building theories from case study research. Academy of Management Review, 14(4): 532-550.

Earl, M.J. (1994) Putting information technology in its place: a polemic for the nineties. In R.G. Galliers and B.S.H. Baker (eds.) Strategic Information Management: Challenges and Strategies in Managing Information Systems. Butterworth Heinemann, Oxford, pp76-90.

Earl, M.J. (1996) An Organisational Approach to IS Strategy-Making. In M.J. Earl (ed.) Information Management: The Organizational Dimension. Oxford University Press, Oxford.

Edwards, C., Ward, J. and Bytheway, A. (1995) The Essence of Information Systems. 2nd ed. Prentice Hall, London.

Farbey, B., Land, F. and Targett, D. (1993) How to assess your IT investment: a study of methods and practice. Butterworth Heinemann, Oxford.

Galliers, R.D., Merali, Y. and Spearing, L. (1994) Coping with information technology? How British executives perceive the key information systems management issues in the mid 1990s. Journal of Information Technology, 9(3).

Hochstrasser, B. and Griffiths, C. (1991) Controlling IT Investment: Strategy and Management. Chapman \& Hall, London.

McKague, A. (1998) Time has Come to Deal with Issue of IT Failures. Computing Canada, June 8.

McKay, J. and Marshall, P. (2000) The IT Evaluation and benefits Management Life Cycle. In W. Van Grembergen (ed.) Information technology Evaluation Methods and Management. Idea Publishing Group, Hershey.

Peppard, J. and Wrad, J. (1999) 'Mind the Gap': Diagnosing the relationship between the IT organization and the rest of the business. Journal of Strategic Information Systems, 8(1): 29-60.

Peters, G. (1994) Evaluating your computer investment strategy. In L. Willcocks (ed.) Information Management: The Evaluation of Information Systems Investments. Chapman and Hall, London.

Remenyi, D.S.J., Money, A., and Twite, A. (1993) A Guide to Measuring and Managing IT Benefits. 2nd ed. NCC Blackwell, Oxford.

Shane, B., Lafferty, P. and Beasley, T. (1999) IM/IT governance framework. Optimum, the Journal of Public Sector Management, 29(2/3): 30-35.

Strassmann, P.A. (1997) The Squandered Computer; Evaluating the Business Alignment of Information Technologies. Information Economics Press, New Canaan, Connecticut.

Thorp, J. (1998) The Information Paradox: Realizing the Benefits of Information Technology. McGraw Hill, Toronto.

Tozer, E.E. (1996) Strategic IS/IT Planning. Butterworth Heinemann, Boston.

Ward, J. and Griffiths, P. (1996) Strategic Planning for Information Systems. $2^{\text {nd }}$ Edition Wiley, Chichester.

Ward, J. and Peppard, J. (2002) Strategic Planning for Information Systems. $3^{\text {rd }}$ Edition, Wiley, Chichester. 
Ward, J. and Peppard, J. (1996) Reconciling the IT/Business relationship: a troubled marriage in need of guidance. Journal of Strategic Information Systems, 5(1): 37-65.

Ward, J., Taylor, P. and Bond, P. (1996) Evaluation and realisation of IS/IT benefits: an empirical study of current practice. European Journal of Information Systems, 4(1996): 214-225.

Weill, P. and Woodham, R. (2002) Don't just lead, govern: implementing effective IT governance. Center for Information Systems Research Working Paper No. 326, Sloan School of Management, MA.

Willcocks, L. (1992) Evaluating Information Technology Investments: Research Findings and Reappraisal. Journal of Information Systems (1992)2: 243-268.

Willcocks, L. (1994) Introduction: of capital importance. In L.Willcocks (ed.) Information Management. Chapman and Hall, London.

Willcocks, L. (1996) Introduction: beyond the IT productivity paradox. In L.Willcocks (ed.) Investing in Information Systems: Evaluation and Management. Chapman and Hall, London.

Willcocks, L. and Lester, S. (1997) Assessing IT productivity: any way out of the labyrinth? In Willcocks, L., Feeny, D.F. \& Islei, G. (Eds.) Managing IT as a Strategic Resource. McGraw-Hill, London. 